\title{
A New Regulatory Locus of the Maltose Regulon in Klebsiella pneumoniae Strain K21 Identified by the Study of Pullulanase Secretion Mutants
}

\author{
By MICHAEL G. KORNACKER, ${ }^{1,2 *}+$ ALAN BOYD, ${ }^{1} \ddagger$ \\ ANTHONY P. PUGSLEY ${ }^{2}$ AND GRAHAM S. PLASTOW 1,3 \\ ${ }^{1}$ The Leicester Biocentre, University of Leicester, University Road, Leicester LE1 7RH, UK \\ ${ }^{2}$ Unité de Génétique Moléculaire, Institut Pasteur, 25 rue du Dr Roux, \\ 75724 Paris Cedex 15, France \\ ${ }^{3}$ Dalgety PLC, Group Research Laboratory, Station Road, Cambridge CB1 2JN, UK
}

(Received 3 August 1988; revised 4 October 1988; accepted 28 October 1988)

\begin{abstract}
This study has shown that Klebsiella pneumoniae strain K21 differs from the previously characterized and closely related $K$. pneumoniae strain PAP996 in that expression of the pullulanase gene ( $p u l A)$ and other genes of the maltose regulon is partially independent of exogenous inducer (maltose/maltotriose). Mutants of strain $\mathrm{K} 21$ which are defective in pullulanase synthesis and/or secretion were isolated following Tn 10 mutagenesis. Three phenotypic classes of mutants were identified. Class I mutants were defective in the surface localization and secretion of pullulanase. Class II mutants did not secrete detectable levels of pullulanase but were able to export pullulanase to the cell surface. Class II mutants also expressed pullulanase and other maltose-regulated genes at markedly lower levels than those found in the parent strain under non-inducing conditions. The single class III mutant was intermediate between $\mathrm{K} 21$ and class I mutants; most of the cell-associated pullulanase was localized at the cell surface whilst a significant amount was secreted into the medium. Mapping indicated that all but three of the Tn 10 insertions were adjacent to, and at either side of, pulA. One class II mutant carried a Tn 10 insertion in or close to malT whereas in the remaining class II mutants the insertions were located at least $4 \mathrm{~kb}$ upstream of $p u l A$ in a region which may define a new regulatory locus of the maltose operon.
\end{abstract}

\section{INTRODUCTION}

Pullulanase (EC 3.2.1 .41) hydrolyses $(1 \rightarrow 6) \alpha$-linkages in $(1 \rightarrow 4) \alpha-,(1 \rightarrow 6) \alpha$-linked glucans and is synthesized and secreted by strains of the Gram-negative bacterium Klebsiella pneumoniae but not by Escherichia coli (Konishi et al., 1979). Pullulanase synthesis is maltose-inducible (Bender \& Wallenfels, 1966; Michaelis et al., 1985; Chapon \& Raibaud, 1985; Raibaud \& Richet, 1987) and the cognate gene, pul $A$, is thus a component of the maltose regulon whose genes are required for the uptake and metabolism of maltose and maltodextrins. In $E$. coli, and at least in part also in K. pneumoniae (Woehner \& Woeber, 1978b; Bloch \& Raibaud, 1986a), the maltose regulon includes the linked malT and malPQ genes, the linked malK-lamB-malM and malEFG operons (Schwartz, 1987) as well as the malS gene (Freundlieb \& Boos, 1986). Expression of all genes is positively regulated by the product of the malT gene, which is interchangeable between $E$. coli and K.pneumoniae (Michaelis et al., 1985; Bloch \& Raibaud, 1986a). Expression of at least some genes of the maltose regulon is enhanced by another positive regulator, the complex of the $c r p$

\footnotetext{
† Present address: Unité de Génétique Moléculaire, Institut Pasteur, 25 rue du Dr Roux, 75724 Paris Cedex 15, France.

$\ddagger$ Present address: Department of Biochemistry, University of Edinburgh Medical School, Hugh Robson Building, George Square, Edinburgh EH8 9XD, UK.
} 
gene product with cAMP (Chapon, 1982), rendering the regulon subject to catabolite repression by glucose (Guidi-Rontani \& Gicquel-Sanzey, 1981). In addition to the classical component genes of the maltose regulon, $K$. pneumoniae also encodes the malT-inducible malX operon, which includes some pullulanase secretion genes (d'Enfert et al., 1987b) and an additional maltose-inducible but malT-independent maltose uptake system (Schwartz, 1987; Bloch \& Raibaud, $1986 b$ ).

Pullulanase has a predicted molecular mass of approximately $117 \mathrm{kDa}$ (Katsuragi et al., 1987). In most strains, pullulanase is first exported to the cell surface where it accumulates until it is slowly released into the medium (Woehner \& Woebner, 1978a; d'Enfert et al., 1987b). Functions required to export pullulanase to the cell surface and to release it into the medium have recently been shown to be encoded by genes on either side of pulA on the chromosome of $K$. pneumoniae strain UNF5023 (d'Enfert et al., 1987b).

In this report we describe the isolation and characterization of three classes of $\operatorname{Tn} 10$ insertion mutants of $K$. pneumoniae strain K21 defective in the synthesis and/or secretion of pullulanase. This strain is unusual in that a large proportion of the pullulanase it produces is rapidly released into the medium and does not appear to pass through a membrane-anchored transition state (Kornacker et al., 1988). Our results essentially confirm but also complement the findings of d'Enfert et al. (1987b). In addition, we show that strain K21, in contrast to all other previously characterized strains of $K$. pneumoniae, is partially constitutive for the expression of genes of the maltose regulon. We also present evidence for the existence of a new regulatory locus of the maltose regulon. This locus is located upstream of pulA and its inactivation results in the same phenotype as that resulting from inactivation of the malT locus.

\section{METHODS}

Media and culture conditions. Bacterial strains are listed in Table 1. Bacterial cultures were grown in Luria broth (Miller, 1972) or M63 medium (Miller, 1972) containing Casamino acids $(0.4 \%)$ and glycerol $(0.4 \%$ or $0.8 \%$ depending on the presence or absence of additional sugars, respectively) and supplemented with maltose or glucose (both $0.4 \%$ ) as indicated. $E$. coli and $K$. pneumoniae strains were grown at $37^{\circ} \mathrm{C}$ and $28^{\circ} \mathrm{C}$, respectively. Antibiotic selection was as appropriate. The amounts used per $\mathrm{ml}$ were : chloramphenicol $(\mathrm{Cm}), 300 \mu \mathrm{g}$; ampicillin (Ap), $100 \mu \mathrm{g}$; tetracycline (Tc), $10 \mu \mathrm{g}$; kanamycin (Km), $25 \mu \mathrm{g}$.

Southern analysis. Chromosomal DNA from mutants was isolated as described by Plastow et al. (1986) and digested to completion using appropriate restriction enzymes. DNA was then separated on a $0.8 \%$ agarose gel.

Table 1. Bacterial strains, bacteriophages and plasmids

$\begin{aligned} & \text { Strain/phage/ } \\ & \text { plasmid }\end{aligned}$
E. coli
5K
MC4100
K. pneumoniae
K21
PAP996
UNF5023
Phage
$\lambda_{840}$
Plasmids
pACYC184
pKGW
pUN121
pMG1
pGSP1
p9MT

Characteristics

$\mathrm{F}^{-}$thi thr leuB6 lacY tonA21 supE44 $\lambda^{-} \mathrm{r}_{\mathrm{K}}^{-} \mathrm{m}_{\mathrm{K}}^{+}$

$\mathrm{F}^{-}$araD139 $\Delta($ argF-lac $) U 169$ rpsL150 relA1 fbB5301 deoCl ptsF 25 rbsR

$\lambda^{\mathrm{r}} \mathrm{Ap}^{\mathrm{r}}$ pulA $\mathrm{A}^{+}$prototrophic

A non-mucoid derivative of ATCC15050

his

$C_{1857}, P_{a m} ;$ carries a derivative of $\operatorname{Tn} 10$

Cloning vector

Positive selection vector

Positive selection vector

Derivative of plasmid pHCP2 (Clement et al., 1982) which

carries the $\mathrm{Km}^{r}$ marker of pUC-4K in its PstI site

Derivative of pACYC184 carrying pulA on the cloned

chromosomal $E_{1}-E_{2}$ fragment of strain K21 (Fig. 3)

Derivative of pBR322 carrying the $\mathrm{Km}^{\mathrm{r}}$ marker of pUC-4K

in the PstI site and the malT gene of pOM25 (Cole \&

Raibaud, 1986) inserted between the EcoRI and SalI site

\section{Source/reference}

Laboratory stock

Laboratory stock

Laboratory stock

Pugsley et al. (1986)

d'Enfert et al. (1987b)

Way et al. (1984)

Chang \& Cohen (1978)

Kuhn et al. (1986)

Nilsson et al. (1983)

This study

This study

This study 
Southern blot procedures were essentially as described by Maniatis et al. (1982), using the probes indicated in the text. Probes were radiolabelled by the method of Feinberg \& Vogelstein (1983). Hybridizations were carried out overnight at $55^{\circ} \mathrm{C}$ (using the malT probe) or $65^{\circ} \mathrm{C}$ (using the lamB probe and those used for mapping $\mathrm{Tn} 10$ insertions) and were washed with $6 \times \mathrm{SSC}$ or $4 \times \mathrm{SSC}$, respectively $(1 \times \mathrm{SSC}$ was $0 \cdot 15 \mathrm{M}$ - $\mathrm{NaCl}, 0.015 \mathrm{M}$-sodium citrate).

Construction of a $\lambda$-sensitive $\left(\lambda^{s}\right)$ derivative of strain $K 21$. A $\lambda^{\text {s }}$ derivative of strain $\mathrm{K} 21$ was constructed as described for Erwinia spp. by Salmond et al. (1986), except that plasmid pMG1 (Table 1) was used instead of plasmid pHCP2 (Clement et al., 1982), since plasmid pHCP2 only specifies resistance to Ap, to which strain K21 is resistant.

Conjugal plasmid transfer into strain K21. Plasmids pMG1 and p9MT were transferred into strain K21 essentially as described by Salmond et al. (1986), except that K21-transconjugants were isolated by selecting for Km-resistant prototrophs on M9-glucose plates (Miller, 1972).

Cloning of chromosomal DNA fragments from strain K21. Chromosomal DNA from strain K21 was isolated, digested to completion with EcoRI, HindIII or $B g I I I$ and ligated to pACYC184, pUN121 or pKGW (each digested with the corresponding enzyme), respectively. For the ligation with pUN121, chromosomal DNA of $6 \mathrm{~kb}$ and greater was isolated on a $20-40 \%(\mathrm{w} / \mathrm{v})$ sucrose gradient (Maniatis et al., 1982). All ligation mixtures were transformed into $E$. coli $5 \mathrm{~K}$. A clone (carrying pGSP1) able to ferment pullulan was identified by its purple colour when transformants from the appropriate ligation were screened on MacConkey plates containing pullulan as the sole carbon source. Recombinant clones obtained from the other ligations were screened by colony hybridization (Maniatis et al., 1982), using the $6 \mathrm{~kb} \mathrm{E}_{1}-\mathrm{E}_{2}$ fragment (see Fig. 3) as a probe.

Enzyme assays. Pullulanase was assayed essentially as described by Hope \& Dean (1974) except that incubations were at $37^{\circ} \mathrm{C}$ in sodium phosphate buffer $(0.1 \mathrm{M}, \mathrm{pH} 7.0)$. Total cellular activity was assayed using sonicated and lysed cells (using $1 \%$ octyl polyoxyethylene), which give identical results (data not shown). Activity is defined as $\mathrm{nmol}$ maltotriose liberated $\mathrm{min}^{-1}$ (mg protein $)^{-1}$. Maltose uptake by maltose permease was measured by following the incorporation of $\left[\mathrm{U}^{-14} \mathrm{C}\right]$ maltose $\left(185 \mathrm{mCi} \mathrm{mmol}^{-1}, 6.8 \mathrm{GBq} \mathrm{mmol}^{-1}\right.$; Amersham) into cultures grown to $\mathrm{OD}_{600}=0.5$ in M63 minimal medium supplemented with Casamino acids and glycerol with or without maltose (all at $0.4 \%$ ). A $2 \mathrm{ml}$ sample of each culture was washed and resuspended in $0.9 \mathrm{ml}$ M63 medium containing Casamino acids $(0.4 \%)$. After incubation for $3 \mathrm{~min}$ at $37^{\circ} \mathrm{C}, 0.1 \mathrm{ml}$ unlabelled maltose $\left(10^{-3} \mathrm{M}, 10^{-4} \mathrm{M}\right.$ and $\left.10^{-5} \mathrm{M}\right)$ containing $10^{5}-10^{6}$ c.p.m. of $\left[\mathrm{U}^{-14} \mathrm{C}\right]$ maltose was added. Samples $(0 \cdot 1 \mathrm{ml})$ were taken at intervals and the incorporation of $\left[\mathrm{U}^{-14} \mathrm{C}\right]$ maltose was determined by scintillation counting. One unit of activity is defined as the uptake of $10^{3}$ c.p.m. min $^{-1}$ (mg protein) $)^{-1}$. Amylomaltase was assayed essentially as described by Raibaud et al. (1985) except that GOD-PAP reagent (Boehringer, grade II) contained 0.5 mM 4-aminophenazone, $0.6 \mathrm{~mm}$ chlorophenol, 12 units glucose oxidase $\mathrm{ml}^{-1}$ and 6 units peroxidase $\mathrm{ml}^{-1}$ in $0 \cdot 2 \mathrm{M}$-Tris, $0 \cdot 2 \mathrm{M}$-sodium phosphate, $\mathrm{pH} 8.0$. Activity is defined as nmol glucose liberated $\min ^{-1}$ (mg protein $)^{-1}$. The halo assay was as described by Morgan et al. (1979). The red pullulan test was as in d'Enfert et al. (1988). Pullulan-reactive red was prepared as in Rinderknecht et al. (1967). $\alpha$-Amylase activity in $K$. pneumoniae was detected by streaking bacterial strains on LB plates (Miller, 1972) containing 0.4\% amylose. These plates were incubated until confluent growth occurred and then stained with iodine vapour. Staining and the absence of staining were interpreted to be due to the inability or ability, respectively, of bacteria to degrade amylose. Plates streaked with E. coli (strain MC4100), which synthesizes a periplasmic $\alpha$-amylase (Freundlieb \& Boos, 1986), gave a negative result. The areas directly under the colonies of $K$. pneumoniae did not stain. This positive result together with the absence of haloes surrounding those colonies was therefore assumed to be due to $\alpha$-amylase that was located on the cell surface but was not secreted.

Other methods. Immunofluorescence and immunoprecipitation experiments were as described by d'Enfert $e t$ al. (1987a). Cell envelopes were isolated as described by Churchward \& Holland (1976) or Pugsley \& Oudega (1987). Envelope fractionation was carried out with Sarkosyl according to Filip et al. (1973). SDS-PAGE analysis was as described by Laemmli (1970), using 0.8\% $N, N^{\prime}$-methylene bisacrylamide. Proteins were stained with Coomassie Brilliant Blue. Protein was determined by the Lowry technique. Transposon mutagenesis was as described by Way et al. (1984) except that the multiplicity of infection was $10^{2}-10^{3}$ in order to obtain sufficient Tc-resistant colonies to allow large-scale screening for pullulanase export mutants.

\section{RESULTS}

\section{Pullulanase production by $K$. pneumoniae strain $\mathrm{K} 21$}

Several lines of evidence suggest that strain $\mathrm{K} 21$ is closely related to $K$. pneumoniae strain PAP996, a derivative (Pugsley et al., 1986) of the previously studied strain ATCC 15050 (Michaelis et al., 1985; Chapon \& Raibaud, 1985; d'Enfert et al., 1987a). Firstly, total cell protein extracts of strain K21 gave SDS-PAGE profiles which were almost identical to those obtained with strain PAP996 but differed markedly from those obtained with strain UNF5023 


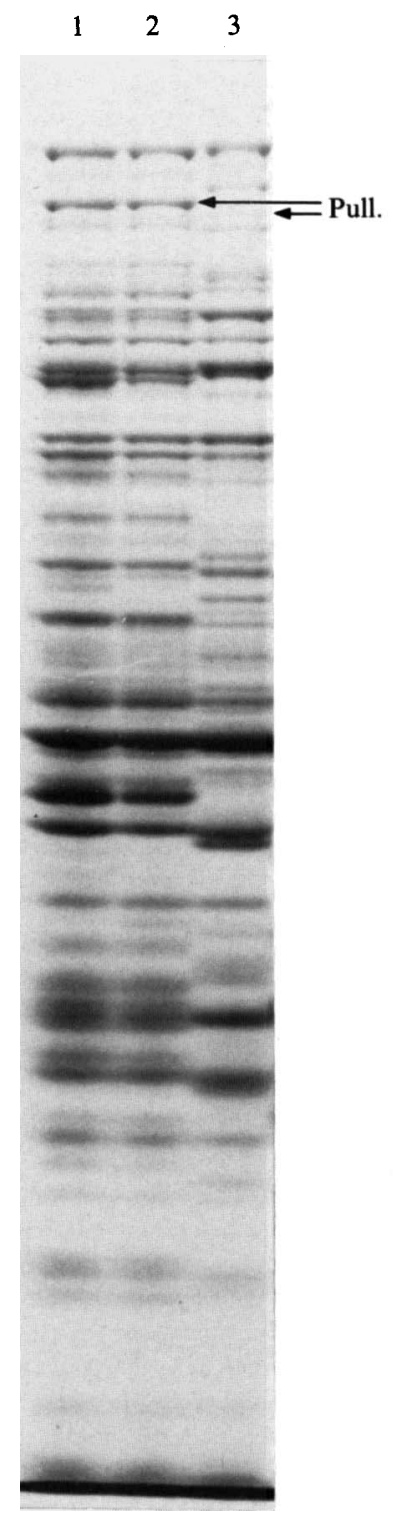

Fig. 1. Comparison of protein profiles of strains of $K$. pneumoniae (lane 1, strain K21 ; lane 2, strain PAP996; lane 3, strain UNF5023). Strains were grown in M63 medium containing glycerol and maltose. Protein in cell lysates was separated by SDSPAGE $(10 \%, w / v$, acrylamide). Pullulanase (Pull.) is indicated by arrows. Pullulanase of strain UNF5023 has a slightly lower apparent molecular mass than pullulanase of strains K21 and PAP996.

(d'Enfert et al., 1987b) (Fig. 1) and other klebsiellae (not shown). Secondly, we have cloned a $6 \mathrm{~kb} E c o \mathrm{RI}$ fragment encoding the pulA gene of strain K21 and found that its restriction endonuclease map is almost identical to that of the corresponding region of the ATCC 15050 chromosome (Michaelis et al., 1985). Furthermore, the DNA sequence of the $5^{\prime}$ end of the K21 pulA gene, its promoter region and the $5^{\prime}$ end of the divergently transcribed mal $X$ gene (Chapon \& Raibaud, 1985; G. S. Plastow, unpublished results), are almost identical to those of strain ATCC 15050 and differ markedly from those of strains UNF5023 (d'Enfert et al., 1987 b) and W70 (Katsuragi et al., 1987). However, strain K21 differs from all previously characterized strains of $K$. pneumoniae (d'Enfert et al., 1987a; Takizawa \& Murooka, 1985) in that high levels of pullulanase are produced in the absence of maltose.

To study this property in more detail, we examined total cell protein extracts of strains $\mathrm{K} 21$ and PAP996 grown in the presence of maltose or glucose. These tests showed that glucose repressed the synthesis of pullulanase and at least two other proteins (molecular masses $48 \mathrm{kDa}$ 

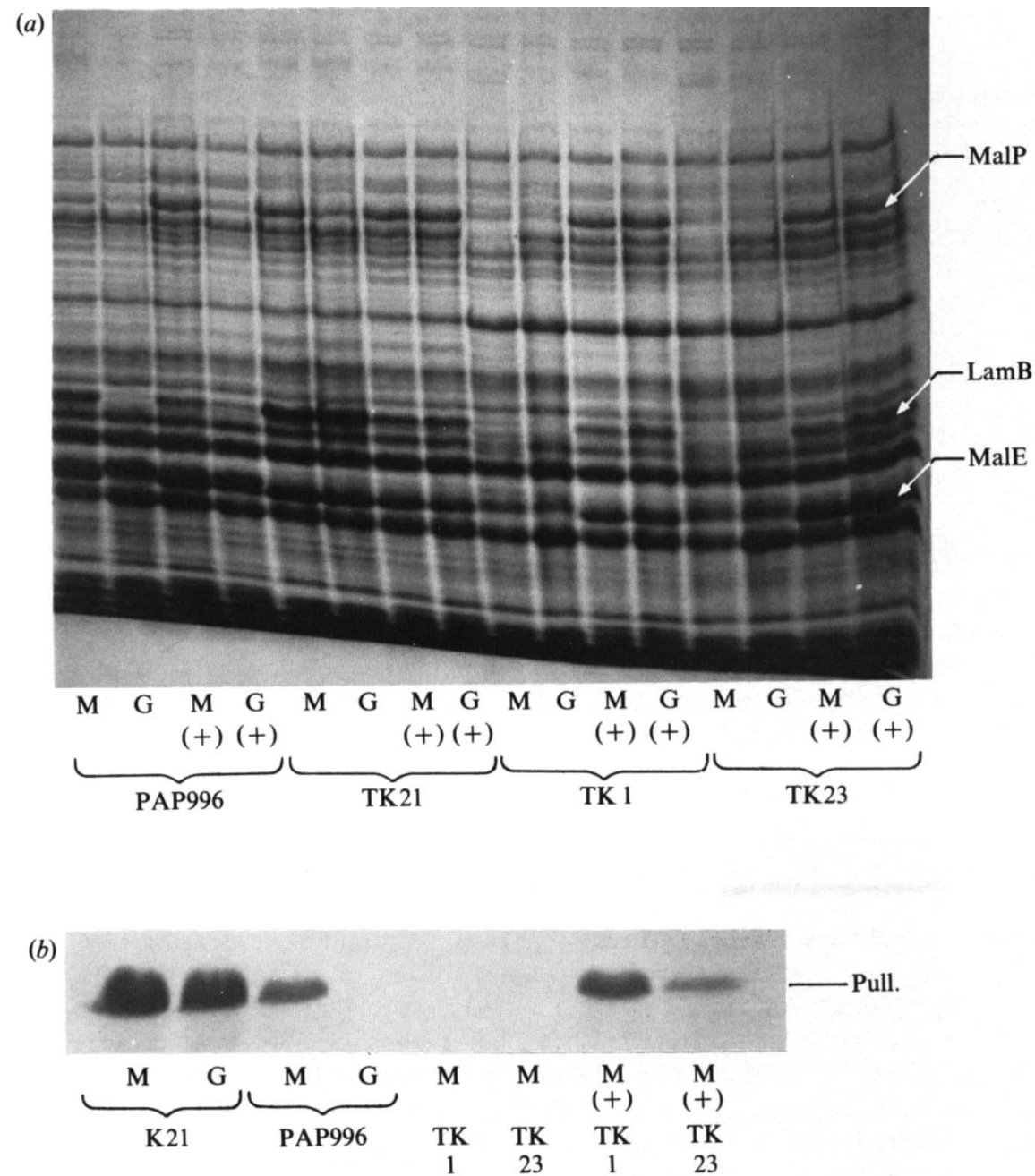

Fig. 2. Comparison by SDS-PAGE analysis $(10 \%$, w/v, acrylamide) of $(a)$ synthesis of maltodextrin phosphorylase (MalP), maltose porin (LamB) and maltose-binding protein (MalE), and (b) secretion of pullulanase in strains K21, PAP996 and linked (TK1) and unlinked (TK23) class II mutants of strain K21. Strains carrying additional plasmid-borne copies of malT are indicated by $(+)$. Bacteria were grown in Luria broth containing glucose $(G)$ or maltose $(M)$ as indicated. The amounts of cells and culture supernatants loaded were equivalent to $0.1 \mathrm{ml}$ and $5 \mathrm{ml}$ of the original culture volume, respectively. The position of the malP gene product has been deduced by comparison with $E$. coli (Bloch \& Raibaud, 1986a). Maltose-binding protein is largely obscured by other protein. Pullulanase is not visible in whole-cell lysates.

and $40 \mathrm{kDa}$ ) to a far greater extent in strain PAP996 than in strain K21 (Fig. 2). The latter two proteins correspond to the equivalents in $K$. pneumoniae of the maltose-inducible $E$. coli lamB and $m a l E$ gene products, respectively, since they could be specifically immunoprecipitated using polyclonal antibodies against the respective $E$. coli proteins, and they were found by cell fractionation to be localized in the outer membrane and non-envelope fractions, respectively (not shown). The low degree of repression exerted by glucose in strain $\mathrm{K} 21$ suggests that maltoseindependent production of pullulanase by strain $\mathrm{K} 21$ resulted from constitutive expression of the entire maltose regulon. This was confirmed by comparing the inducibility of the mal $Q$ gene product, amylomaltase, in strains K21 and PAP996; induction in strain K21 was only fourfold when grown in medium containing maltose (Table 2), whereas induction was at least 50-fold for 
Table 2. Determination of pullulanase (pulA) and amylomaltase (malQ) activities in strains $K 21$ and PAP996

Strains were grown to $\mathrm{OD}_{600}=3$ in M63 medium containing glycerol and supplemented with sugars as appropriate. Activities were determined using sonicated whole cultures.

\begin{tabular}{|c|c|c|c|}
\hline \multirow[b]{2}{*}{ Strain } & \multirow{2}{*}{$\begin{array}{c}\text { Carbon } \\
\text { source }\end{array}$} & \multicolumn{2}{|c|}{ Units of activity* } \\
\hline & & Pullulanase & Amylomaltase \\
\hline $\mathrm{K} 21$ & $\begin{array}{l}\text { Glycerol } \\
\text { Glucose } \\
\text { Maltose }\end{array}$ & $\begin{array}{r}68 \cdot 9 \\
66 \cdot 3 \\
108 \cdot 0\end{array}$ & $\begin{array}{r}86 \cdot 2 \\
90 \cdot 3 \\
345 \cdot 0\end{array}$ \\
\hline PAP996 & $\begin{array}{l}\text { Glycerol } \\
\text { Glucose } \\
\text { Maltose }\end{array}$ & $\begin{array}{l}<1 \cdot 3 \\
<1 \cdot 3 \\
63 \cdot 7\end{array}$ & $\begin{array}{l}<5.0 \\
<5 \cdot 0 \\
232.5\end{array}$ \\
\hline
\end{tabular}

strain PAP996. Similar results were obtained when pullulanase was assayed (Table 2). Furthermore, although stationary-phase cultures of strains K21 and ATCC 15050 contain similar amounts of pullulanase under inducing conditions, in the absence of inducer pullulanase synthesis can only be detected for $\mathrm{K} 21$ (not shown). Since the pulA, malQ, lamB and malE genes are in different operons of the maltose regulon (Schwartz, 1987), these results suggest that expression of the entire maltose regulon of strains $\mathrm{K} 21$ is partially constitutive.

Isolation and characterization of mutants of strain K21 that are defective in pullulanase synthesis and secretion

As part of our study of pullulanase synthesis and secretion by strain K21, mutants defective in secretion were isolated by $\lambda:: \operatorname{Tn} 10$ mutagenesis. A $\lambda^{\text {s }}$ derivative of strain $\mathrm{K} 21$ was constructed as described in Methods, and was subjected to transposon mutagenesis using $\lambda_{840}$ (Way et al., 1984). Approximately 5000 colonies were screened for defects in pullulanase secretion and/or synthesis using a plate haloassay (Morgan et al., 1979). A total of 22 mutants able to synthesize pullulanase but defective in its secretion were isolated. They represent at least 18 different $\mathrm{Tn} 10$ insertions as judged by Southern blot analysis (see below).

All of the Tn 10 insertion mutants that were isolated were defective in the secretion of pullulanase as determined by pullulanase assays and by the pullulanase-reactive-red plate test (d'Enfert et al., 1988) (Table 3). However, they fell into three classes with respect to the level of synthesis of pullulanase and other components of the maltose regulon, growth on maltose, immunofluorescence and immunoprecipitation experiments and the proportion of pullulanase found on the cell surface (Table 3).

Although class I mutants synthesized almost wild-type levels of pullulanase, most of the activity was 'cryptic' (i.e. not detectable with intact cells), with very little activity present on the cell surface. These mutants are therefore defective in cell-surface localization of pullulanase. In addition, there was no detectable secretion of pullulanase into the culture medium.

Class II mutants exhibited levels of pullulanase that were less than $5 \%$ of those seen in the parent strain K21. Pullulanase assays suggested that class II mutants were capable of exporting most of the pullulanase made to the cell surface. Pullulanase was not detectable in the culture medium as judged by pullulanase assays (Table 3) and SDS-PAGE analysis of concentrated culture media (not shown), even though amounts lower than $5 \%$ of the amount secreted by wildtype K21 would have been detectable. The low amounts of pullulanase synthesized presumably prevented its detection on the cell surface by immunofluorescence (Table 3). Class II mutants were further distinguished by their slow growth on maltose as the sole carbon source, by the absence of an apparently maltose-inducible $\alpha$-amylase activity on the cell surface and by an altered profile of total cell protein as determined by SDS-PAGE analysis (Fig. 2). The reduced production of maltose porin and maltose-binding protein (see above, Fig. 2) was particularly noticeable. Class II mutants were also strongly impaired in maltose uptake (Table 3), 
Table 3. Comparison of properties of strain K21 and the three classes of Tn10 insertion mutants

For details see text. All assays were repeated at least once.

\begin{tabular}{|c|c|c|c|c|}
\hline & K21 & Class I & Class II & Class III \\
\hline $\begin{array}{l}\text { Units* of pullulanase activity } \\
\text { Percentage of pullulanase }\end{array}$ & 65 & $44 \cdot 2-59 \cdot 9$ & Percentage of pullulanase & $50 \cdot 8$ \\
\hline In culture medium & 60 & 0 & 0 & 40 \\
\hline On cell surface & 40 & $10-20$ & $60-100$ & 36 \\
\hline Cryptic $†$ & $\mathbf{0}$ & $80-90$ & $0-40$ & 24 \\
\hline Immunofluorescence with anti-PulA & $++t$ & - & - & +++ \\
\hline \multicolumn{5}{|l|}{ Units* of maltose uptake } \\
\hline With $10^{-5} \mathrm{M}$-maltose & $28 \cdot 3$ & ND & $1 \cdot 2$ & ND \\
\hline With $10^{-6} \mathrm{M}$-maltose & $98 \cdot 7$ & ND & $1 \cdot 2$ & ND \\
\hline Units* of amylomaltase (malQ) activity & $317 \cdot 5$ & $210-257 \cdot 5$ & $<5$ & $231 \cdot 0$ \\
\hline Cell surface $\alpha$-amylase activity & $++t$ & +++ & - & +++ \\
\hline Growth on maltose & +++ & ++ & + & +++ \\
\hline \multicolumn{5}{|l|}{ Immunoprecipitation } \\
\hline $\begin{array}{l}\text { LamB protein } \\
\text { MalE protein }\end{array}$ & $\begin{array}{l}+++ \\
+++\end{array}$ & $\begin{array}{l}+++ \\
+++\end{array}$ & - & $\begin{array}{l}+++ \\
+++\end{array}$ \\
\hline \multicolumn{5}{|l|}{ Plate tests } \\
\hline $\begin{array}{l}\text { Halo assay } \\
\text { Pullulan red }\end{array}$ & $\begin{array}{l}+++ \\
+++\end{array}$ & - & - & $\begin{array}{c}++ \\
+\end{array}$ \\
\hline
\end{tabular}

ND, Not determined.

* Units of activity and uptake are defined in Methods.

$\dagger$ Cryptic activity is defined as pullulanase activity that is not accessible by assaying whole cells resuspended in fresh medium.

presumably due to low or absent expression of maltose permease genes. The pleiotropic nature of the class II mutants suggested a defect in the induction of all maltose-inducible proteins.

Only one class III mutant was isolated. In the halo assay this mutant produces a smaller halo than the parent strain. The class III mutant synthesized near-normal levels of pullulanase, and was shown to contain 'cryptic' activity. However, in contrast to the class I mutants, the class III mutant localized most of the cell-associated pullulanase to the cell surface. In addition, a significant amount of pullulanase (up to $40 \%$ of total activity in some experiments, see Table 3 ) was found in the culture medium, indicating that secretion in this mutant is impaired but not completely abolished.

\section{Mapping of the sites of Tn10 insertion in mutant strains}

To determine if any of the genes identified by the Tn10 insertions were linked to the pulA gene, the $6 \mathrm{~kb} \mathrm{E}_{1}-\mathrm{E}_{2}$ fragment (Fig. 3) of pGSP1 carrying pulA (see Methods) was used as a probe in Southern blot analysis of genomic DNA isolated from Tn 10 insertion mutants. This allowed the $\mathrm{Tn} 10$ insertions to be mapped with respect to known restriction sites inside and outside this fragment. Of the 22 mutants isolated, 12 class I mutants and the single class III mutant carried insertions within the $E c o$ RI fragment. There were five and four class I insertions, respectively, at each side of the unique BamHI site $\left(\mathrm{B}_{2}\right)$ (Fig. 3), with the class III mutant mapping in the $E_{1}-B_{2}$ fragment. The remaining three insertions (class I mutants TK13, TL14 and TK61) have not been mapped with respect to this BamHI site. In each case the size of the novel EcoRI fragments generated by insertion of the transposon suggests two possible insertion sites: one outside pulA and one within it. Since all of the mutants synthesized pullulanase and since Tn 5 insertions (Michaelis et al., 1985; G. S. Plastow, unpublished results) and deletions (Takizawa \& Murooka, 1985) throughout the entire length of pulA prevent synthesis of an active pullulanase, we conclude that the Tn 10 insertions must be located outside pulA. At least one class I mutant, TK66 (see below), carries an insertion within the $6 \mathrm{~kb} E c o$ RI fragment but clearly is not in the $E_{1}-G_{2}$ restriction fragment that includes pulA (Fig. 3). Furthermore, Southern blot analysis (data not shown) shows that strain K21 carries only one copy of the pulA gene; the 


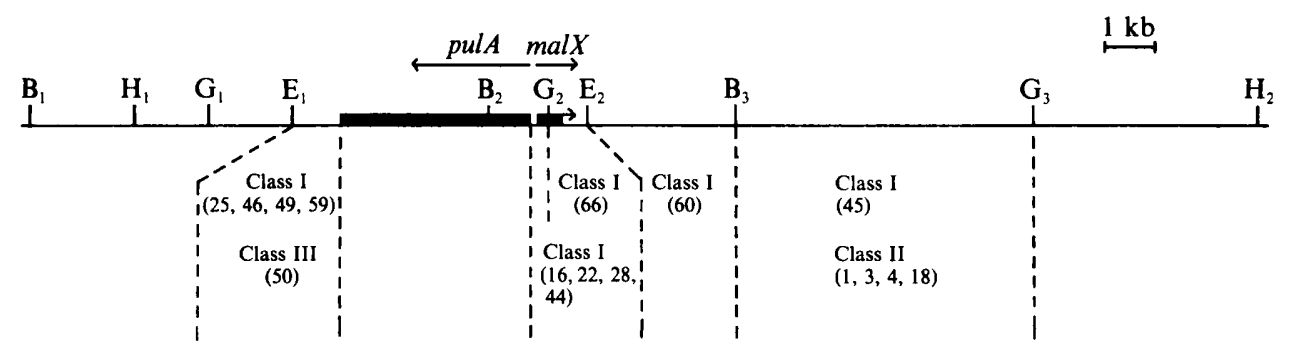

Fig. 3. Positions of $\mathrm{Tn} 10$ insertions in the pulA region of strain $\mathrm{K} 21$. The vertical broken lines indicate chromosomal regions to which mutants have been mapped. Mutants are referred to by their class and are listed in parentheses underneath. Mutants TK13, TK14, TK61 and unmapped mutants (TK23, TK42, TK48) are not shown. The positions of pulA and $\mathrm{mal} X$ are indicated by the solid bars (the size of malX is not known). Their directions of transcription are indicated by the arrows. The positions of restriction sites outside the $6 \mathrm{~kb} E c o \mathrm{RI}_{1}-E c o \mathrm{RI}_{2}$ fragment were deduced by Southern blot analysis and by restriction analysis of the chromosomal DNA fragments of strain K21 that were isolated in this study (see text). Restriction sites are: B, BamHI; G, BglII; E, EcoRI; H, HindIII.

continuing ability of the $\mathrm{Tn} 10$ insertion mutants to synthesize pullulanase cannot therefore be due to the presence of other pulA genes.

To see whether the remaining $\mathrm{Tn} 10$ insertions were adjacent to the $6 \mathrm{~kb} E c o \mathrm{RI}$ fragment, DNA flanking pulA was cloned into pKGW as two $B g l \mathrm{II}$ fragments of $6.5 \mathrm{~kb}\left(\mathrm{G}_{1}-\mathrm{G}_{2}\right)$ and $10 \mathrm{~kb}$ $\left(\mathrm{G}_{2}-\mathrm{G}_{3}\right)$. In addition, a $22.5 \mathrm{~kb}$ HindIII fragment $\left(\mathrm{H}_{1}-\mathrm{H}_{2}\right)$ was cloned into pUN121 (Fig. 3) (see Methods). These fragments, or subclones thereof, were used as probes in further mapping experiments. Seven additional Tn 10 insertions were mapped (Fig. 3): (a) using BglII-digested chromosomal DNA of mutant TK66 (class I) and the $\mathrm{G}_{2}-\mathrm{E}_{2}$ fragment as a probe, the insertion in this mutant was assigned to within the $\mathrm{G}_{2}-\mathrm{E}_{2}$ fragment; (b) the insertion in mutant TK60 (class I) was assigned to within the $E_{2}-B_{3}$ fragment following hybridization of the $B_{2}-E_{2}$ and $\mathrm{E}_{1}-\mathrm{E}_{2}$ probes to BamHI- or EcoRI-digested chromosomal DNA, respectively; and $(c)$ the insertions within one class I mutant (TK45) and four class II mutants (TK1, TK 3, TK4, TK 18) were assigned to within the $B_{3}-G_{3}$ fragment following hybridization of the $B_{2}-E_{2}$ and $G_{2}-G_{3}$ probes to BamHI- and $B g / \mathrm{II}$-digested DNA, respectively. The four class II mutants are probably identical since they were isolated from the same mutagenesis experiment and could not be distinguished by Southern blot analysis. Two class I mutants (TK42 and TK48) and another class II mutant (TK23) did not map within the $\mathrm{B}_{1}-\mathrm{H}_{2}$ fragment (Fig. 3).

The mapping data for the class $I$ mutants indicate that genes required for secretion of pullulanase are located on either side of pulA. However, unlike strain UNF5023 (d'Enfert et al., $1987 \mathrm{~b}$ ) at least one of these genes (see mutants TK42/48) is not adjacent to pulA.

The class III mutant may carry an insertion in a locus downstream of pulA that is distinct from the locus inactivated in the class I mutant carrying $\mathrm{Tn} 10$ insertions in the same region. Alternatively, its phenotype may result from partial inactivation of a locus that is completely inactivated in the adjacent class I mutants.

The mapped class II mutations are not in malT, cya, crp or maltose transport genes

In $E$. coli, inactivation of malT, the maltose transport genes, cya and crp are known to affect expression of all components of the maltose regulon in the way seen for our $K$. pneumoniae class II mutants (Schwartz, 1987). Using the malT gene of $E$. coli as a probe in Southern blot analysis, it was found that genomic DNA of the unmapped class II mutant TK23 gave rise to a pattern of hybridizing fragments that was consistent with a Tn10 insertion in or close to malT (Fig. 4). As expected, hybridization was not detectable in digests of the $\mathrm{H}_{1}-\mathrm{H}_{2}$ fragment.

Using $\operatorname{lam} B$ of $E$. coli as a probe, it was found that the gene for the maltose porin of $K$. pneumoniae does not map within the $\mathrm{H}_{1}-\mathrm{H}_{2}$ fragment. This almost certainly rules out the possibility that the mapped class II Tn10 insertions are located in any of the maltose transport genes. This was confirmed by the finding that synthesis of pullulanase, maltose porin and 


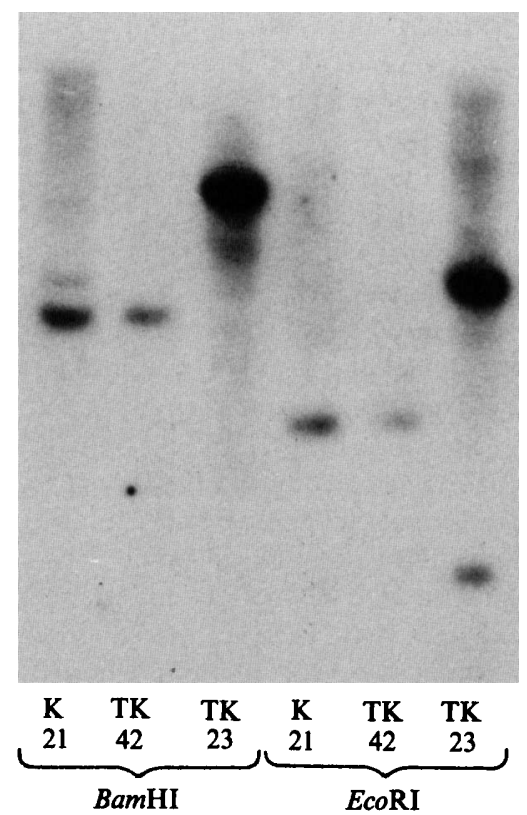

Fig. 4. Southern blot demonstrating Tn10 insertion in or close to malT of class II mutant TK23. Chromosomal DNA from strain K21 or class I mutant TK42 served to identify the wild-type hybridization pattern. Chromosomal DNA was digested with EcoRI or BamHI, respectively. $\lambda_{840}$ carries a derivative of Tn 10 which has a single EcoRI site and no BamHI site. Insertion in an EcoRI or $B a m H I$ fragment carring malT will therefore result in the generation of two hybridizing bands or one hybridizing band whose increase in size relative to the wild-type corresponds to the size of the $\mathrm{Tn} 10$ derivative, respectively. The amounts of DNA loaded were approximately $1-2 \mu \mathrm{g}$ of chromosomal DNA, $200 \mathrm{ng}$ of plasmid pHi (not shown) or $3 \mathrm{ng}$ of probe (the $3.5 \mathrm{~kb}$ EcoRI-Sall fragment of pOM25; Cole \& Raibaud, 1986) (not shown). No hybridization was detectable in digests of plasmid pHi (not shown). Hybridization to the probe gave a strong signal (not shown). E, EcoRI; B, BamHI.

maltose-binding protein (and the secretion of pullulanase) could all be restored in the mapped class II mutants by introducing a multiple-copy-number plasmid carrying malT (see Table 1) which cannot substitute for structural components of the maltose regulon (Fig. 2) (see Discussion). Class II mutants exhibited normal expression of the lac operon (not shown). Since expression of the lac operon is dependent on cya and crp, this rules out these genes as sites for the Tn 10 insertions in the linked class II mutants. It follows that the pulA-linked class II mutants carry $\operatorname{Tn} 10$ insertions in a new regulatory element of the maltose regulon.

\section{DISCUSSION}

Our analysis of pullulanase secretion mutants obtained by $\mathrm{Tn} 10$ mutagenesis of $\mathrm{K}$. pneumoniae strain K21 essentially agrees with that of d'Enfert et al. (1987b), who studied pullulanase secretion by a different approach, i.e. the mutagenesis of a cloned fragment in $E$. coli. We also find that genes for export of pullulanase to the cell surface and for its secretion are genetically linked to pulA in the chromosome of strain K21, as is the case for K. pneumoniae strain UNF5023 (d'Enfert et al., 1987b). In fact, class I Tn10 insertions of strain K21 are phenotypically similar or identical to transposon insertions in regions $\mathrm{B}$ and $\mathrm{C}$ (located downstream and upstream of pulA, respectively) in the region of the UNF5023 chromosome studied by d'Enfert et al. (1987b). However, strain K21 differs from strain UNF5023 in that at least one class I pullulanase secretion gene does not map close to pulA. This may explain why $E$. coli carrying the chromosomal $\mathrm{H}_{1}-\mathrm{H}_{2}$ fragment of strain $\mathrm{K} 21$ does not secrete pullulanase although export to the cell surface does occur (Kornacker et al., 1988). Nevertheless, it remains to be established why 
the $E$. coli strain is able to expose pullulanase on the cell surface whereas mutants TK42 and TK48 are not. Interestingly, we were unable to isolate mutants of strain K21 with Tn10 insertions leading to a pulA ${ }^{-}$phenotype even though a large number of $\operatorname{Tn} 10$ insertions were clustered around pulA.

Class II mutants are defective in the expression of the maltose regulon. Mutants with such a phenotype were not isolated by d'Enfert et al. $(1987 \mathrm{~b})$. We do not know whether the Tn10 insertions in the class II mutants that map adjacent to pulA are in a gene or allele that is unique to strain K21 or to $K$. pneumoniae because mutants with transposon insertions in the same locus would not have been isolated in the study by d'Enfert $e$ t $a l .(1987 \mathrm{~b})$ if the corresponding gene was also present in $E$. coli. The phenotypes of all class II mutants are identical whether they carry $\mathrm{Tn} 10$ insertions in malT or in the locus that is located upstream of pulA. As expected, a wild-type phenotype can be restored in the malT:: $\mathrm{Tn} 10$ mutant by (over)production of MalT from a multicopy plasmid. However, this is also the case in the pulA-linked class II mutants. With respect to the latter, this may be equivalent to the suppression by overproduction of MalT of the effects on maltose regulon expression that are caused by catabolite repression (Chapon, 1982) or the fact that maltose-regulon expression is maltose-independent in $E$. coli strains carrying multiple copies of malT. This suggests that the locus affected in the pulA-linked class II mutants encodes a positive regulator of the maltose regulon analogous to that encoded by the $c r p$ gene. Indeed, if the Tn 10 insertions in the linked class II mutants affected expression of a negative regulator, an increase in expression of the maltose regulon would be predicted and this is clearly not the case. The ability of malT to substitute for this regulator probably rules out that the latter is involved in the expression of the alternative malT-independent maltose-uptake system that has recently been identified in $K$. pneumoniae (Bloch \& Raibaud, 1986b). The restoration by malT of pullulanase secretion in all class II mutants demonstrates that expression of pullulanasesecretion genes is not subject to polar effects by the Tn10 insertions in these mutants. It is not known why class II mutants fail to secrete the residual levels of pullulanase from the cell surface.

The locus affected in the pulA-linked class II mutants could theoretically correspond to malM, a maltose-inducible gene of unknown function that has been identified in $E$. coli (Gilson et al., 1986). However, this is unlikely since, at least in $E$. coli, malM is linked to lamB. We also consider it unlikely that the $\mathrm{Tn} 10$ insertions are in genes such as malI that are required for the synthesis of endogenous inducers because we do not observe induction of the maltose regulon by maltose as is the case for malI ::Tn10 strains of E. coli (Ehrmann \& Boos, 1987). In addition, we were unable to demonstrate by Southern blot analysis any hybridization of the $\mathrm{H}_{1}-\mathrm{H}_{2}$ fragment with the chromosomal fragment of $E$. coli that carries malI (unpublished data). We therefore suggest that the pulA-linked class II Tn 10 insertions are in a previously unknown regulatory locus of the maltose regulon. The reason for the partial constitutivity of strain $\mathrm{K} 21$ remains to be established, but may be related to the fact that strain $\mathrm{K} 21$ is an industrial strain that has been selected for efficient production of pullulanase.

This work was supported by a SERC-CASE studentship to M.G.K. in collaboration with Dalgety PLC, and by CNRS and MRT grants to M. Schwartz. Anti-MalE was a gift from W. Boos. The DNA fragment carrying mall was generously provided by M. Ehrmann. Octyl polyoxyethylene was a gift from J. Rosenbusch. C. d'Enfert provided pullulan-reactive red. He and $O$. Raibaud are thanked for helpful discussions.

\section{REFERENCES}

Bender, H. \& W ALlenfels, K. (1966). Pullulanase (an amylopectin and glucogen debranching enzyme) from Aerobacter aerogenes. Methods in Enzymology 8, 555-559.

Bloch, M. A. \& Raibaud, O. (1986a). Comparison of the malA regions of Escherichia coli and Klebsiella pneumoniae. Journal of Bacteriology 168, 1220-1227.

Bloch, M. A. \& RaIbaud, O. (1986b). Caracterisation preliminaire d'un nouveau système permettant l'assi- milation du maltose par Escherichia coli. Annales de l'Institut Pasteur/Microbiologie 137, 145-153.

Chang, A. C. Y. \& Cohen, S. N. (1978). Construction and characterisation of amplifiable multicopy DNA cloning vehicles derived from the P15A cryptic miniplasmid. Journal of Bacteriology 134, 1141-1156.

CHAPON, C. (1982). Role of the catabolite activator protein in the maltose regulon of $E$. coli. Journal of Bacteriology 150, 722-729. 
Chapon, C. \& Raibaud, O. (1985). Structure of two divergent promoters located in front of the gene encoding pullulanase in Klebsiella pneumoniae and positively regulated by the malT product. Journal of Bacteriology 164, 639-645.

Churchward, G. G. \& Holland, I. B. (1976). Envelope synthesis during the cell cycle in $E$. coli. Journal of Molecular Biology 105, 245-261.

Clement, J. M., Perrin, D. \& Hedgepeth, J. (1982). Analysis of $\lambda$ receptor and $\beta$-lactamase synthesis and export using cloned genes in a minicell system. Molecular and General Genetics 185, 302-310.

Cole, S. T. \& Raibaud, O. (1986). The nucleotide sequence of the malT gene encoding the positive regulator of the Escherichia coli maltose regulon. Gene 42, 201-208.

EHRMANN, M. \& Boos, W. (1987). Identification of endogenous inducers of the mal regulon in Escherichia coli. Journal of Bacteriology 169, 3539-3545.

D'Enfert, C., Chapon, C. \& Pugsley, A. P. (1987a). Export and secretion of the lipoprotein pullulanase by Klebsiella pneumoniae. Molecular Microbiology 1 , 107-116.

D'Enfert, C., Ryter, A. \& Pugsley, A. P. (1987b). Cloning and expression in E. coli of the Klebsiella pneumoniae genes for production, surface localisation and secretion of the lipoprotein pullulanase. EMBO Journal 6, 3531-3538.

D'Enfert, C., Reyss, I., Ryter, A. \& Pugsley, A. P. (1988). Pullulanase: a new specific secretion pathway in Escherichia coli. In Membrane Biochemistry, pp. 419-428. Edited by J. Op den Kamp. Berlin \& Heidelberg: Springer Verlag.

Feinberg, A. P. \& Vogelstein, B. (1983). A technique for radiolabelling DNA restriction endonuclease fragments to high specific activity. Analytical Biochemistry 132, 6-13.

Filip, C., Fletcher, G., Wulff, J. L. \& Earhart, C. (1973). Solubilisation of the cytoplasmic membrane of Escherichia coli by an ionic detergent sodium lauryl sarcosinate. Journal of Bacteriology 115, 717722.

FREUNDLIEB, S. \& Boos, W. (1986). $\alpha$-Amylase of $E$. coli, mapping and cloning of the structural gene, mals, and identification of its product as a periplasmic protein. Journal of Biological Chemistry 261, 2946-2953.

Gilson, E., Rousset, J. P., Charbit, A., Perrin, D. \& HofNuNG, M. (1986). malM, a new gene of the maltose regulon in Escherichia coli $\mathrm{K}-12$. Journal of Molecular Biology 191, 303-311.

Guidi-RonTanI, C. \& GicQuel-SANZey, B. (1981). Expression of the maltose regulon in strains lacking the cyclic AMP-receptor protein. FEMS Microbiological Letters 10, 383-387.

Hope, G. C. \& Dean, A. C. R. (1974). Pullulanase synthesis in Klebsiella (Aerobacter) aerogenes strains growing in continuous culture. Biochemical Journal 144, 403-411.

Katsuragi, N., Takizawa, N. \& Murooka, Y. (1987). Entire nucleotide sequence of the pullulanase gene of Klebsiella aerogenes W70. Journal of Bacteriology 169, 2301-2306.

Konishi, Y., Amemura, A., Tanabe, S. \& Harada, T. (1979). Immunological study of pullulanase from Klebsiella strains and the occurrence of this enzyme in the Enterobacteriaceae. International Journal of Systematic Bacteriology 29, 13-18.

Kornacker, M. G., Boyd, A. \& Plastow, G. S. (1988). A genetic analysis of pullulanase export from Klebsiella aerogenes. In Membrane Biochemistry, pp. 429-438. Edited by J. Op den Kamp. Berlin \& Heidelberg: Springer Verlag.

KuhN, I., Stephenson, F., Boyer, H. W. \& Green, P. J. (1986). Positive-selection vectors utilizing lethality of the EcoRI endonuclease. Gene 44, 253263.

LAEMMLI, U. K. (1970). Cleavage of structural proteins during the assembly of the head of bacteriophage T4. Nature, London 227, 680-685.

Maniatis, T., Fritsch, E. F. \& Sambrook, J. (1982). Molecular Cloning, a Laboratory Manual. Cold Spring Harbor, NY: Cold Spring Harbor Laboratory.

Michaelis, S. C., Chapon, C., D'Enfert, C., PugsLEY, A. P. \& SCHWARTZ, M. (1985). Characterisation and expression of the structural gene for pullulanase, a maltose-inducible secreted protein of Klebsiella pneumoniae. Journal of Bacteriology 164, 633-638.

Miller, J. H. (1972). Experiments in Molecular Genetics. Cold Spring Harbor, NY: Cold Spring Harbor Laboratory.

Morgan, F. J., Adams, K. R. \& Priest, F. G. (1979). A cultural method for the detection of pullulandegrading enzymes in bacteria and its application to the genus Bacillus. Journal of Applied Bacteriology 46, 291-294.

Nilsson, B., Uhlen, M., Josephson, S., Gatenbeck, S. \& Philipson, L. (1983). An improved positive selection plasmid vector constructed by oligonucleotide mediated mutagenesis. Nucleic Acids Research 11, 8019-8030.

Plastow, G. S., Border, P. M., Hinton, J. C. D. \& SALMOND, G. P. C. (1986). Molecular cloning of pectinase genes from Erwinia carotovora subspecies carotovora strain SCRI193. Symbiosis 2, 115-122.

Pugsley, A. P. \& Oudega, B. (1987). Methods for studying colicins and their plasmids. In Plasmids, $a$ Practical Approach, pp. 105-160. Edited by K. G. Hardy. Oxford: IRL Press.

Pugsley, A. P., Chapon, C. \& Schwartz, M. (1986). Extracellular pullulanase of Klebsiella pneumoniae is a lipoprotein. Journal of Bacteriology 166, 1083-1088.

RAIBAUD, O. \& RICHET, E. (1987). Maltotriose is the inducer of the maltose regulon of Escherichia coli. Journal of Bacteriology 169, 3059-3061.

Raibaud, O., Gutierrez, C. \& Schwartz, M. (1985). Essential and nonessential sequences in $\operatorname{malP}_{\mathrm{p}}$, a positively controlled promoter in Escherichia coli. Journal of Bacteriology 161, 1201-1208.

RiNDERKNECHT, H., WILDING, P. \& HAVERBACK, P. J. (1967). A new method for the detection of $\alpha$-amylase. Experientia 23, 805-807.

Salmond, G. P. C., Hinton, J. C. D., Gill, D. R. \& Perombelon, M. C. M. (1986). Transposon mutagenesis of Erwinia using phage $\lambda$ vectors. Molecular and General Genetics 203, 524-528.

SchwaRTZ, M. (1987). The maltose regulon. In Escherichia coli and Salmonella typhimurium, Cellular and Molecular Biology, pp. 1482-1502. Edited by F. C. Neidhardt, J. L. Ingraham, K. B. Low, B. Magasanik, M. Schaechter \& H. E. Umbarger. Washington, DC: American Society for Microbiology. 
Takizawa, N. \& Murooka, Y. (1985). Cloning of the pullulanase gene and overproduction of pullulanase in Escherichia coli and Klebsiella aerogenes. Applied and Environmental Microbiology 49, 294-298.

Way, J. C., Davis, M. A., Morisato, D., Roberts, D. E. \& KLeCKNER, N. (1984). New Tn10 derivatives for transposon mutagenesis and for construction of $l a c Z$ operon fusions by transposition. Gene 32, 369-379.
Woehner, G. \& Woeber, G. (1978a). Pullulanase, an enzyme of starch catabolism, is associated with the outer membrane of Klebsiella. Archives of Microbiology 116, 303-310.

Woehner, G. \& Woeber, G. (1978b). Subcellular distribution of enzymes involved in $\alpha$-glucan utilisation in Klebsiella pneumoniae. Archives of Microbiology 116, 311-316. 